\title{
Olley and Pakes-style Production Function Estimators with Firm Fixed Effects
}

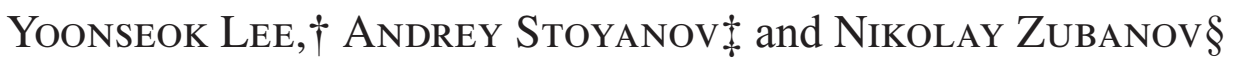 \\ $\dagger$ Department of Economics and Center for Policy Research, Syracuse University, 426 \\ Eggers Hall, Syracuse, NY 13244, USA (e-mail: ylee41@maxwell.syr.edu) \\ $\$$ Department of Economics, Faculty of Liberal Arts and Professional Studies, York \\ University, 1084 Vari Hall, 4700 Keele St. Toronto, M3J 1P3, Canada (e-mail: \\ andreyst@yorku.ca) \\ $\S$ Faculty of Economics and Business Administration, University of Konstanz, \\ Universitätstrasse 10, Konstanz, Germany (e-mail: nick.zubanov@uni-konstanz.de)
}

\begin{abstract}
We show that control function estimators (CFEs) of the firm production function, such as Olley-Pakes, may be biased when productivity evolves with a firm-specific intercept, in which case the correctly specified control function will contain a firm-specific term, omitted in the standard CFEs. We develop an estimator that is free from this bias by introducing firm fixed effects in the control function. Applying our estimator to the data, we find that it outperforms the existing CFEs in terms of capturing persistent unobserved heterogeneity in firm productivity. Our estimator involves minimal modification to the standard CFE procedures and can be easily implemented using common statistical software.
\end{abstract}

\section{Introduction}

Much of the empirical literature on firm-level productivity relies on estimating the production function. A well-known problem in this literature is what Griliches and Mairesse (1998) call the transmission bias - a bias in input elasticity estimates caused by a correlation between factor inputs and unobserved firm productivity. Olley and Pakes (1996) introduced a control function estimator (CFE) which has become a popular remedy to this bias. Their approach was to control for the correlation between factor inputs and unobserved firm productivity by approximating the latter with a function of observed firm choice variables - such as investment or materials input - that reflect the firm's reaction to productivity changes.

Several studies have since emerged, extending the classical Olley-Pakes CFE (CFEOP) estimator to address its limitations. However, the available control function-based estimators (CFEs) still rely on a number of assumptions which are rarely tested. Among those is the assumption that total factor productivity (TFP) follows a first-order Markov 
process that is homogeneous for all firms; that is, $\omega_{i t}=E\left[\omega_{i t} \mid \omega_{i t-1}\right]+v_{i t}$, where $\omega$ is the TFP, $v$ 's are independent and identically distributed (i.i.d.) shocks, and $i$ and $t$ are firm and time indicators, respectively. In this paper, we extend this assumption to include a firmspecific unobserved heterogeneity term $\eta_{i}$, specifying $\omega_{i t}=E\left[\omega_{i t} \mid \omega_{i t-1}, \eta_{i}\right]+v_{i t}$, argue that this extension may be relevant empirically, and show that the conventional CFEs will be inconsistent unless all $\eta_{i}=0$. We then derive a CFE with firm fixed effects (CFE-FE) that controls for $\eta_{i} \neq 0$ and apply it to manufacturing firm data from Chile and Denmark.

Our work is motivated by three facts. First, substantial and persistent productivity differences between firms have long been seen in the data (Bartelsman and Doms, 2000; Syverson, 2011). Yet, the available CFEs lack controls for firm heterogeneity in TFP. This deficiency, which has been recognized as one of the serious limitations of the CFE approach (Eberhardt and Helmers, 2010), may cause transmission bias in the production function estimates. Especially prone to this bias is the coefficient on capital input, since capital is likely to be more highly correlated with the persistent productivity component than other inputs because capital adjustment costs are higher. ${ }^{1}$

Second, as found in Aw (2002), and also present in our data, firm productivity converges to its steady-state level only gradually, and this steady-state level varies by firm. These productivity dynamics are consistent with a Markov process with a firm-specific intercept. Yet, the conventional CFEs assume a productivity specification without an intercept. Third, applying a selection of the conventional CFEs to our data, we find a significant and lasting residual autocorrelation. We attribute this autocorrelation to the presence of a persistent firm-specific TFP component that the conventional CFEs fail to capture.

We derive a set of moment conditions for a consistent CFE under TFP specifications with a firm-specific intercept. Unlike the conventional CFEs, the resulting estimator, CFE-FE, controls for firm fixed effects. Applying CFE-FE to the data, we observe a great reduction in residual autocorrelation, which implies that our estimator captures a large part of the firm-specific persistence in productivity. An additional advantage of our estimator is its conceptual simplicity and ease of implementation: in particular, it can be run using existing Stata commands (see the online Appendix S1 for an example Stata .do file).

In the rest of the paper, we outline the existing CFEs starting with CFE-OP (sections 'The Olley-Pakes estimator (CFE-OP)' and 'Extensions of the Olley-Pakes estimator'), and show how unaccounted persistence in TFP leads to the transmission bias (section 'Persistence in the TFP process and its consequences'). Then, in section III, we explain how introducing fixed effects in the CFE framework can mitigate this bias and derive our estimator, CFE-FE. We apply a selection of CFEs to the Chilean and Danish manufacturing firm data in section IV, showing in particular the large difference in residual autocorrelation between the existing CFEs and CFE-FE. Section V concludes.

\section{Control function-based estimators}

Consider a Cobb-Douglas production function (in logs):

\footnotetext{
${ }^{1}$ Since labour or material input adjustment costs are often relatively low, their response to short-term productivity shocks will be higher than that of capital.
} 


$$
\begin{aligned}
v a_{i t} & =l_{i t} \beta_{l}+k_{i t} \beta_{k}+u_{i t} \\
u_{i t} & =\omega_{i t}+e_{1, i t},
\end{aligned}
$$

where $i, t$ are the firm and year indicators, respectively, $v a_{i t}$ is value added, $l_{i t}$ is the vector of static inputs, such as labour, which can vary freely at each $t, k_{i t}$ is a vector of dynamic inputs, such as capital, which are partly determined by their previous stock. The term $u_{i t}$, unobservable to the econometrician, is the empirical equivalent of Hicks-neutral productivity. It is the sum of total factor productivity (TFP) $\omega_{i t}$, which is observed by the firm and hence affects its input choices, and random noise $e_{1, i t}$, which is unobserved and does not affect input choices. Though $\omega_{i t}$ can be correlated with $l_{i t}$ or $k_{i t}$, we restrict $e_{1, i t}$ to be orthogonal to $l_{i t}, k_{i t}$, and $\omega_{i t}$.

Estimating equation (1) with OLS will result in biased and inconsistent estimates of $\beta_{l}$ and $\beta_{k}$ because a firm's choice of input quantities depends on its TFP: more productive firms will use more, resulting in the transmission bias mentioned in the introduction. One approach to deal with such bias is to approximate TFP with a function of observables, called a control function. This section gives an overview of existing control function estimators (CFEs), outlines the key assumptions required for their consistency, and argues that some of these assumptions are quite strong and unlikely to hold in the data. The next section presents our proposed solution to the failure of some of the assumptions behind the conventional CFEs.

\section{The Olley-Pakes estimator (CFE-OP)}

The Olley and Pakes (1996) CFE-OP estimator deals with the transmission bias by expressing TFP $\left(\omega_{i t}\right)$ as a function of observables (hence the control function). The estimation procedure relies on several assumptions common to other CFEs as we outline below. The original CFE-OP contains a correction for potentially endogenous firm entry and exit, which can be implemented in our setting if necessary. For the sake of simplicity, we do not implement this correction in this paper, focussing instead on the main issue of interest the control function.

Assumption 1. $k_{i t}$ at time $t$ is predetermined, while $l_{i t}$ is freely adjustable for each $t$.

The second part of Assumption 1, regarding the scope for adjusting the labour input $l_{i t}$ as well as other static inputs, is relaxed in later modifications of the CFE-OP which we review in the next subsection.

Assumption 2 ("Scalar unobservability"). The investment level $i_{i t}$ is fully determined by the dynamic inputs $k_{i t}$, TFP $\omega_{i t}$, and, possibly, other observable variables $z_{i t}$.

Under Assumptions 1 and 2, the firm investment level that solves the dynamic profit maximization problem can be represented as a function of $k_{i t}, z_{i t}$, and TFP:

$$
i_{i t}=\phi\left(\omega_{i t}, k_{i t}, z_{i t}\right)
$$

Assumption 3. The investment function $i_{i t}=\phi\left(\omega_{i t}, k_{i t}, z_{i t}\right)$ in equation (2) is monotonic in $\omega_{i t}$. 
Assumption 3 implies that the control function can be specified by inverting the investment function (2) for $\omega_{i t}$ :

$$
\omega_{i t}=g\left(k_{i t}, i_{i t}, z_{i t}\right)
$$

Putting the control function (3) back in the production function (1) gives the first-stage CFE-OP regression:

$$
v a_{i t}=l_{i t} \beta_{l}+k_{i t} \beta_{k}+g\left(k_{i t}, i_{i t}, z_{i t}\right)+e_{1, i t}
$$

The unknown function $g(\cdot)$ is approximated with a polynomial of a fixed (usually third) order in $\left(k_{i t}, i_{i t}, z_{i t}\right)$, denoted $\tilde{g}(\cdot){ }^{2}$ Approximating $g(\cdot)$ with $\tilde{g}(\cdot)$ does not allow $\beta_{k}$ to be estimated from equation (4) but does allow the recovery of the coefficient estimates for static factor inputs, $\hat{\beta}_{l}$, and the estimated composite term $\hat{\Phi}_{i t}$ that captures the TFP and the dynamic inputs,

$$
\Phi_{i t} \equiv \Phi\left(k_{i t}, i_{i t}, z_{i t}\right)=k_{i t} \beta_{k}+g\left(k_{i t}, i_{i t}, z_{i t}\right),
$$

from the following first-stage regression:

$$
v a_{i t}=l_{i t} \beta_{l}+\Phi\left(k_{i t}, i_{i t}, z_{i t}\right)+e_{1, i t} .
$$

Estimating $\beta_{k}$ requires an additional assumption on TFP:

Assumption 4. $\omega_{i t}$ follows the first-order Markov process: $\omega_{i t}=E\left[\omega_{i t} \mid \omega_{i t-1}\right]+e_{2, i t}$, where $e_{2, i t}$ is an innovation term satisfying $E\left[e_{2, i t} \mid \omega_{i t-1}\right]=0$.

Under Assumption 4, for a given $\beta_{l}$, it follows from equation (1) that

$$
E\left[v a_{i t}-l_{i t} \beta_{l} \mid k_{i t}, \omega_{i t-1}\right]=k_{i t} \beta_{k}+E\left[\omega_{i t} \mid k_{i t}, \omega_{i t-1}\right]+E\left[e_{1, i t}+e_{2, i t} \mid k_{i t}, \omega_{i t-1}\right]
$$

and $E\left[e_{1, i t}+e_{2, i t} \mid k_{i t}, \omega_{i t-1}\right]=0$ by construction, since $k_{i t}$ is pre-determined from Assumption 1 and $e_{1, i t}$ is orthogonal to $\left(l_{i t}, k_{i t}, \omega_{i t}\right)$. The regression

$$
v a_{i t}-l_{i t} \beta_{l}=k_{i t} \beta_{k}+E\left[\omega_{i t} \mid \omega_{i t-1}\right]+e_{i t}
$$

with $e_{i t}=e_{1, i t}+e_{2, i t}$ is then well-defined and has no endogeneity problem. Letting $E\left[\omega_{i t} \mid\right.$ $\left.\omega_{i t-1}\right]=h\left(\omega_{i t-1}\right)$ and noting that $\omega_{i t-1}=\Phi_{i t-1}-k_{i t-1} \beta_{k}$ from equations (3) and (5), $\beta_{k}$ can be consistently estimated from the second- stage regression

$$
v a_{i t}-l_{i t} \hat{\beta}_{l}=k_{i t} \beta_{k}+h\left(\hat{\Phi}_{i t-1}-k_{i t-1} \beta_{k}\right)+e_{i t},
$$

with the unknown function $h(\cdot)$ again approximated by a fixed-order polynomial and $\hat{\beta}_{l}$ and $\hat{\Phi}_{i t-1}$ obtained from the first-stage regression (6).

\section{Extensions of the Olley-Pakes estimator}

Several limitations of CFE-OP have been identified since it was introduced, motivating other CFEs as its extensions. One such limitation is that in practice many firms report zero

\footnotetext{
${ }^{2}$ As a robustness check, we have also tried a second- and a fourth-degree polynomials, both giving very similar regression estimates and diagnostic statistics. In particular, the shares in the residual variance accounted by the thirdand fourth-degree polynomials in $\left(k_{i t} ; i_{i t} ; z_{i t}\right)$ are within 0.005 from each other.
} 
investment, which casts doubt on the monotonicity of the investment function (Assumption 3). In particular, the presence of capital adjustment costs could violate the monotonicity assumption, making the investment function non-invertible. To address this concern, Levinsohn and Petrin (2003) propose to specify the control function in terms of intermediate inputs, such as materials, which are always positive. Thus, the proxy for productivity in their CFE-LP estimator is

$$
\omega_{i t}=g\left(k_{i t}, m_{i t}, z_{i t}\right),
$$

where $m_{i t}$ is $\log$ materials input. Like investments, materials are chosen optimally by firms given the state variables, but the adjustment costs of materials are arguably lower than of capital investment, so that the monotonicity assumption is less likely to fail.

Another potential problem with CFE-OP and CFE-LP, discussed in Ackerberg, Caves and Frazer (2015), is that the coefficient on labour input may not be identifiable at the first stage. This problem will arise if labour input is optimally chosen by firms upon observing their productivity, in which case it becomes a function $l_{i t}=\varphi\left(k_{i t}, z_{i t}, \omega_{i t}\right)$. Substituting the expression for $\omega_{i t}$ from equation (8), $l_{i t}=\varphi\left(k_{i t}, z_{i t}, g\left(k_{i t}, m_{i t}, z_{i t}\right)\right)$. That is, labour input becomes a function of the same variables as the control function, which precludes identification of its coefficient, $\beta_{l}$, at the first stage. The solution proposed by Ackerberg et al. (2015) is to estimate $\beta_{l}$ from the second stage, using the estimate of the control function from the first stage and Assumption 4. Their procedure amounts to estimating the following (nonlinear) regression equation:

$$
v a_{i t}=l_{i t} \beta_{l}+k_{i t} \beta_{k}+h\left(\hat{\Phi}_{i t-1}-k_{i t-1} \beta_{k}\right)+e_{i t},
$$

which differs from the standard procedure in equation (7) in that the coefficients on capital and labour are estimated together. Wooldridge (2009) proposes a GMM procedure that estimates all the coefficients in the production function in one stage by directly approximating the function $h($.$) in equation (9) with a polynomial in (k, l, m, z)$. This estimator is somewhat simpler to implement because it is linear and does not rely on the estimates of $\Phi($.$) from the first stage, thus avoiding bootstrapping to compute standard errors. The$ linearity of Wooldridge (2009) estimator is particularly important for our purposes because running a nonlinear estimator with high-dimension fixed effects may be computationally challenging.

In our estimation procedure, we combine the choice of the instruments for the control function in CFE-OP and CFE-LP with the flexibility of the Wooldridge (2009) GMM estimator. This combination results in what we label as the OPW estimator that estimates

$$
v a_{i t}=l_{i t} \beta_{l}+k_{i t} \beta_{k}+f\left(k_{i t-1}, m_{i t-1}, z_{i t-1}\right)+e_{i t}
$$

with the moment conditions

$$
E\left(e_{i t} \mid k_{i t}, l_{i t-1}, k_{i t-1}, m_{i t-1}, z_{i t-1}\right)=0,
$$

where $m$ is $\log$ materials input, and $f(\cdot)$ is approximated by a polynomial function in $\left(k_{i t-1}, m_{i t-1}, z_{i t-1}\right){ }^{3}$ We adopt OPW as the baseline estimator in this study.

\footnotetext{
${ }^{3}$ Alternatively, one can estimate the same specification with gross output as the dependent variable, in which case one should use instruments other than the current materials input in the control function (for example, investment).
} 
Yet another potential issue with CFE-OP and CFE-LP is the fragility of the scalar unobservability Assumption 2, the failure of which results in inconsistent estimates. To illustrate, consider CFE-OP and define $r_{i t}=g\left(k_{i t}, i_{i t}, z_{i t}\right)-\tilde{g}\left(k_{i t}, i_{i t}, z_{i t}\right)$ as the difference between TFP $\omega_{i t}=g\left(k_{i t}, i_{i t}, z_{i t}\right)$ and its polynomial approximation $\tilde{g}\left(k_{i t}, i_{i t}, z_{i t}\right)$. In the standard case, $r_{i t}$ will be a part of the regression residuals and can be made arbitrarily small by increasing the degree of the polynomial in $\tilde{g}(\cdot)$. However, if we omit important variables in the investment function $\phi(\cdot)$ (and hence in the control function), $r_{i t}$ will be a function of the omitted variables. In this case $r_{i t}$ cannot be made arbitrarily small by increasing the order of polynomial approximation. Huang and Hu (2011) develop a maximum likelihood estimator that is robust to the presence of measurement error in the proxy variable (or, equivalently, omitted variables in $z_{i t}$ ). Their solution is to use another proxy variable that is independent of the original proxy conditional on unobserved productivity. In their estimation procedure, one proxy variable works as an instrument for the other, producing unbiased control function estimates. Their estimator can outperform the alternatives, such as Ackerberg et al. (2015), in the presence of measurement error in the proxy variable. This type of non-degenerating approximation error problem can also happen when Assumption 4 is violated, which we further explore in the next section.

\section{Persistence in the TFP process and its consequences}

In this section we describe another situation in which existing CFEs will give inconsistent estimates: the presence of firm-specific persistence in TFP. Suppose TFP follows a firstorder Markov process conditional on a time-invariant $\eta_{i}$ with a finite second moment and $E\left[e_{1, i t} \mid \eta_{i}\right]=0$,

$$
\omega_{i t}=E\left[\omega_{i t} \mid \omega_{i t-1}, \eta_{i}\right]+e_{2, i t},
$$

where $e_{2, i t}$ satisfies $E\left[e_{2, i t} \mid \omega_{i t-1}, \eta_{i}\right]=0$. The specification of TFP in equation (12) is a generalization of the first-order Markov condition in Assumption 4 underlying CFE-OP. The existing CFEs all assume homogeneous dynamics in TFP, that is, $\eta_{i}=0$. If in fact $\eta_{i} \neq 0$, the consequence of this assumption is a misspecified second-stage CFE regression (7) which restricts $\eta_{i}=0$ or, equivalently, misspecified moment conditions (11) which omit $\eta_{i}$. These misspecifications will result in inconsistent CFE estimates if factor inputs or proxy variables are correlated with $\eta_{i}$.

Firm-specific persistence in productivity, which is consistent with specification (12), can be observed in the data. For illustrative purposes, take a simple example of equation (12), a first-order stationary autoregressive process with a firm-specific intercept,

$$
E\left[\omega_{i t} \mid \omega_{i t-1}, \eta_{i}\right]=\eta_{i}+\gamma \omega_{i t-1}
$$

with $0<\gamma<1$. The above specification implies that each firm has its steady-state productivity level, $\eta_{i} /(1-\gamma)$, that it gradually approaches. The distinct statistical 'signature' of such a specification is slower productivity growth in older firms which are closer to their steady-state productivity. Aw (2002) finds this pattern in firm data from Taiwan, observing that productivity grows faster in already more productive firms, but this accelerating productivity growth slows down with firm size. As more productive firms tend to be larger, 
(a) Unadjusted
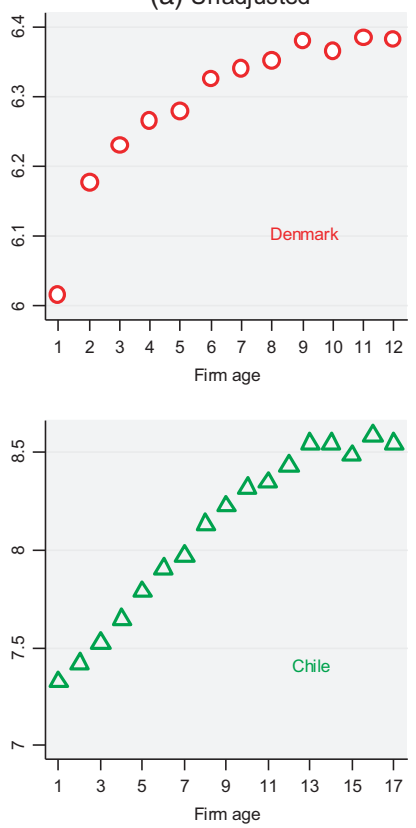

(b) Adjusted for firm survival
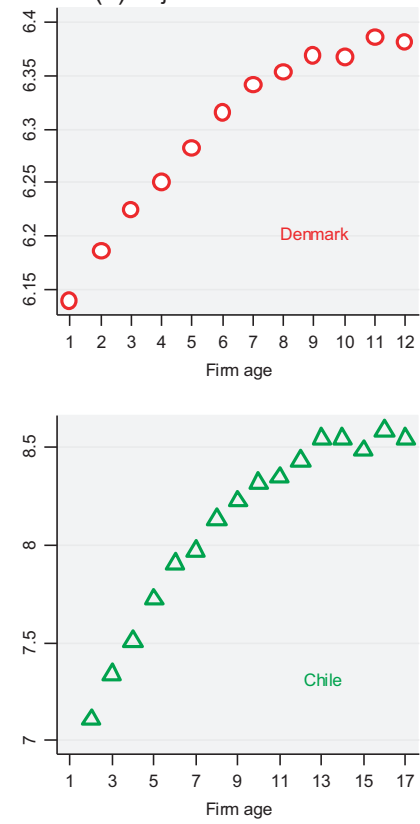

(c) Relative to existing firms
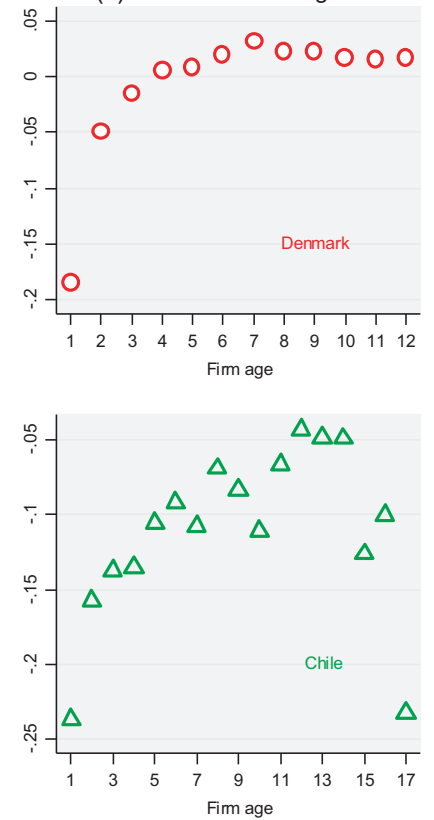

Figure 1. Value added per worker of new firms

the finding of productivity growth decelerating with size implies a gradual convergence of firm productivity to its steady-state level. ${ }^{4}$

We observe similar productivity dynamics in our data, too. Figure 1 reports average productivity by firm age in the Chilean and Danish manufacturing sectors, for three measures: average value added per worker in all firms of a given age (panel A), the same adjusted for firm survival probability (panel B), and the same calculated relative to the average productivity of all firms in a given year (panel C). For all three measures, productivity grows faster in newer firms and slows down as firms get older and bigger. A first-order Markov process without an intercept (Assumption 4) would not generate such productivity patterns, because then the average of the firm productivity levels would fluctuate around some stable level without positive dynamics for newer firms. Moreover, breaking down the sample of market entrants by terciles of TFP in the first year of entry (Figure 2), we find the same dynamic pattern in all terciles, but the productivity levels in different terciles converge to distinctively different values. Hence, not only is there an intercept in TFP but also this intercept is likely firm specific.

\section{The CFE with firm fixed effects}

In this section, we develop a new CFE with firm-fixed effects, labelled CFE-FE. Unlike other CFEs, CFE-FE is consistent in the presence of firm-specific persistence in productivity as specified in equation (12).

\footnotetext{
${ }^{4}$ In our example, productivity converges to its steady-state level from below. In other situations, for example, a temporary positive productivity shock, convergence will be from above. In any case, gradual convergence to a firm-specific steady state would be consistent with the productivity specification in equation (13) rather than that in Assumption 4.
} 

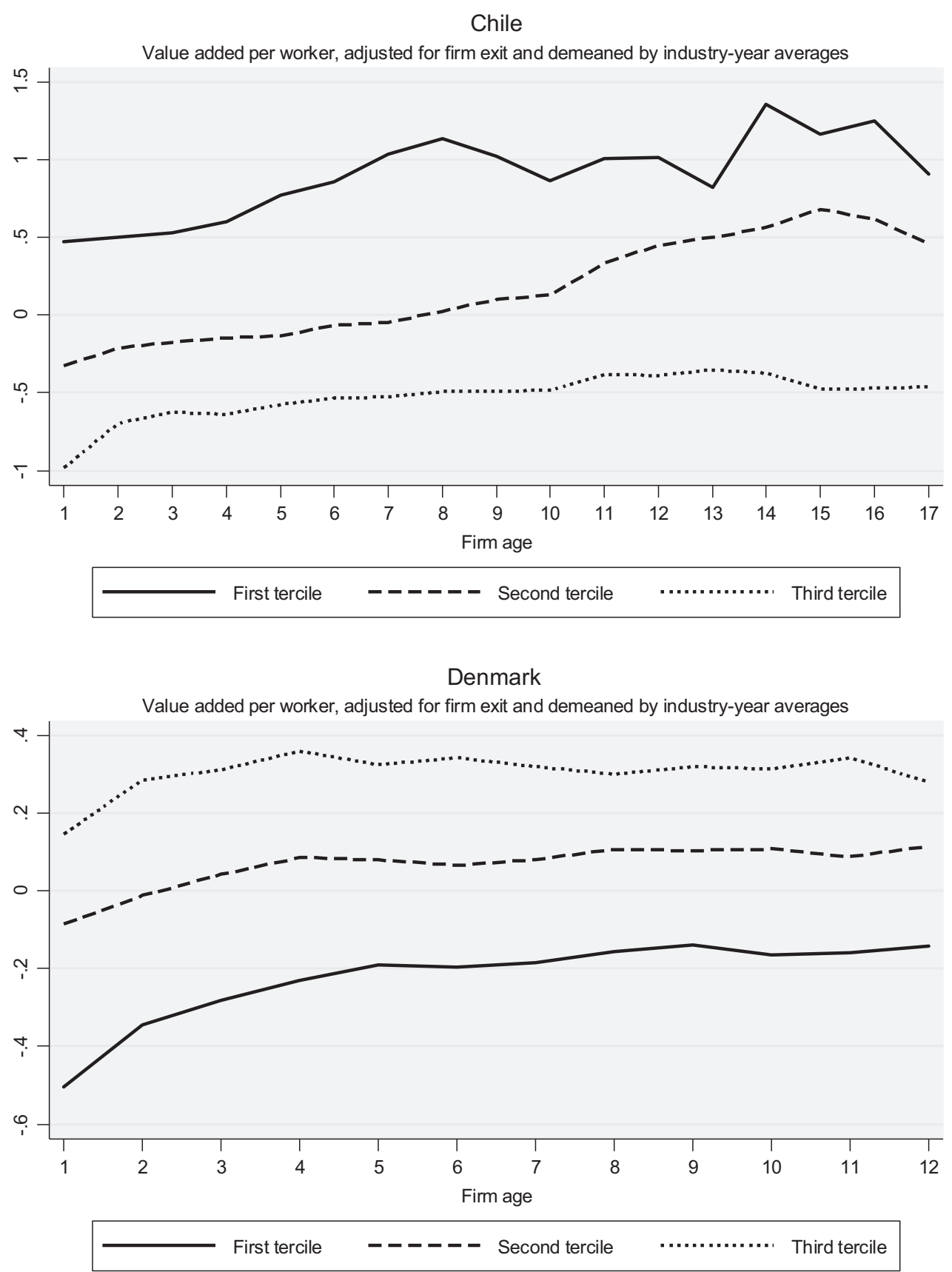

Figure 2. Value added per worker of new firms, by tercile in the year of entry

\section{CFE-FE under firm-specific persistence in productivity}

The estimator we present in this section is based on Assumptions 1-3 and the following generalization of Assumption 4 (recall the TFP specification in equation (12)): 
Assumption 4'. TFP $\omega_{i t}$ follows a first-order Markov process conditional on a timeinvariant random variable $\eta_{i}$ with a finite second moment: $\omega_{i t}=E\left[\omega_{i t} \mid \omega_{i t-1}, \eta_{i}\right]+e_{2, i t}$, where $E\left[e_{2, i t} \mid \omega_{i t-1}, \eta_{i}\right]=0$ and $E\left[e_{1, i t} \mid \eta_{i}\right]=0$.

Unlike the standard CFE approaches, which all assume homogeneous dynamics in TFP, the TFP specification in Assumption 4' allows for firm-specific persistence in TFP through the term $\eta_{i}$. We do not impose any restrictions on the statistical relation between $\omega_{i t-1}$ and $\eta_{i}$; hence they can be arbitrarily correlated with each other. In this sense, we can see $\eta_{i}$ as the fixed effect in panel data models.

We consider a particular version of equation (12) where $E\left[\omega_{i t} \mid \omega_{i t-1}, \eta_{i}\right]=\eta_{i}+h\left(\omega_{i t-1}\right)$ for some unknown function $h(\cdot)$. This way we separate the persistent TFP component, $\eta_{i}$, from the rest of it. This specification yields a nonparametric panel autoregression with fixed effects:

$$
\omega_{i t}=\eta_{i}+h\left(\omega_{i t-1}\right)+e_{2, i t} .
$$

Under the above TFP specification, the first step of the estimation procedure is the same as in other CFEs except for adding the firm fixed effect $\eta_{i}$. One can still estimate $\beta_{l}$ and $\Phi(\cdot)$ from the analogue of the first-stage regression (7) with added fixed effects. Under Assumptions 1-3 and Assumption 4', at the second stage, we have

$$
E\left[v a_{i t}-l_{i t} \hat{\beta}_{l} \mid \omega_{i t-1}, \eta_{i}\right]=k_{i t} \beta_{k}+E\left[\omega_{i t} \mid \omega_{i t-1}, \eta_{i}\right]+E\left[e_{1, i t}+e_{2, i t} \mid \omega_{i t-1}, \eta_{i}\right]
$$

for a given $\hat{\beta}_{l}$ obtained at the first stage and $E\left[e_{1, i t}+e_{2, i t} \mid \omega_{i t-1}, \eta_{i}\right]=0$. By letting $E\left[\omega_{i t} \mid \omega_{i t-1}\right.$, $\left.\eta_{i}\right]=\eta_{i}+h\left(\omega_{i t-1}\right)$ as in equation (14), the regression

$$
\begin{aligned}
v a_{i t}-l_{i t} \hat{\beta}_{l} & =k_{i t} \beta_{k}+E\left[\omega_{i t} \mid \omega_{i t-1}, \eta_{i}\right]+e_{i t} \\
& =\eta_{i}+k_{i t} \beta_{k}+h\left(\omega_{i t-1}\right)+e_{i t}
\end{aligned}
$$

with $e_{i t}=e_{1, i t}+e_{2, i t}$ has no endogeneity problem. Noting that $\omega_{i t-1}=\Phi_{i t-1}-k_{i t-1} \beta_{k}$, we can consistently estimate $\beta_{k}$ from a semiparametric panel regression with a firm-specific fixed effect at the second stage:

$$
v a_{i t}-l_{i t} \hat{\beta}_{l}=\eta_{i}+k_{i t} \beta_{k}+h\left(\hat{\Phi}_{i t-1}-k_{i t-1} \beta_{k}\right)+e_{i t}
$$

with the unknown $h(\cdot)$ approximated by a (fixed-order) polynomial and $\hat{\beta}_{l}$ and $\hat{\Phi}_{i t-1}$ obtained from the first stage.

Alternatively, in the spirit of Wooldridge (2009), all the parameters in the above equation can be estimated in one stage, by running equation (15) where $\hat{\Phi}_{i t-1}$ in $h\left(\hat{\Phi}_{i t-1}-k_{i t-1} \beta_{k}\right)$ is approximated with a polynomial in $\left(k_{i t-1}, m_{i t-1}, z_{i t-1}\right)$ rather than recovered from the first stage, resulting in:

$$
v a_{i t}=\eta_{i}+l_{i t} \beta_{l}+k_{i t} \beta_{k}+f\left(k_{i t-1}, m_{i t-1}, z_{i t-1}\right)+e_{i t},
$$

which is the approach we take. We approximate $f(\cdot)$ with a third-degree polynomial in its arguments. Following Ahn and Schmidt (1995), Arellano and Bover (1995) and Blundell and Bond (1998),we first-difference equation (16) to drop $\eta_{i}$ and estimate the coefficients 
$\beta_{l}, \beta_{k}$, as well as the parameters of the polynomial approximation $\Delta f\left(k_{i t-1}, m_{i t-1}, z_{i t-1}\right)$, from the following moment conditions:

$$
E\left[\Delta e_{i t} \mid x_{i t}\right]=0,
$$

where the set $x_{i t}$ of the excluded instruments contains $\left(l_{i t-2}, k_{i t-1}, m_{i t-2}, z_{i t-1}\right)$ as well as powers and products of its individual elements, all of which are predetermined with respect to $\Delta e_{i t}$ and are thus valid instruments. Notice that by excluding $l_{i t-1}$ and $m_{i t-1}$, our moment conditions remain valid even if labour and materials inputs are dynamic, the possibility raised in Ackerberg et al. (2015). Notice also that, if desired, one can include 'deeper' lags of the original instruments for more recent observations for which they are available, and specify our estimator as a GMM estimator with moment conditions $E\left[\Delta e_{i t} \mid x_{i s}\right]=0$, $s \leqslant t$.

In our specific application of the CFE-FE estimator (results in section IV), we estimate both gross output and value added specifications. In the value added specification, we include labour and capital inputs, and a third-degree polynomial in lagged capital and materials in the control function $f(\cdot)$. We use second lags of labour and materials, their squares and cubes, and all the cross-products of second lags of capital and materials (up to third degree) as excluded instruments. Thus, we have nine excluded instruments for seven endogenous variables. The gross output specification is estimated similarly, except that we include investments in the instrument set because materials are now a factor input.

Remark. Our estimator also allows for a fixed effect $\mu_{i}$ in the first-stage regression (6), as long as it does not interfere with a firm's investment decisions. This term $\mu_{i}$ could stand for some omitted (time-invariant) factors in the production function that the productivity fixed effect $\eta_{i}$ does not capture, for example, persistent measurement error in inputs that may be present in the data. The moment conditions for estimating a specification with $\mu_{i}$ remain the same as in equation (17).

\section{CFE-FE vs. dynamic panel estimators with fixed effects}

The CFE-FE is related to dynamic panel estimators with firm fixed effects. Under equation (14) and the conditions specified in Lee (2014), TFP can be represented as a stationary $\beta$-mixing process conditional on $\eta_{i}$. Specifically, $\omega_{i t}$ can be rewritten as a combination of persistent (time-invariant) and transient (time-varying) elements, $\omega_{i t}=F\left(\eta_{i},\left\{e_{2, i t-j}\right\}_{j=0}^{\infty}\right)$, for some function $F(\cdot, \cdot)$, in which the persistent component of TFP is represented by $\eta_{i}$ and the transient component is represented by a combination of $\left\{e_{2, i t-j}\right\}_{j=0}^{\infty}$. For instance, assuming a linear stationary autoregressive process for TFP as in equation (13), we obtain

$$
\omega_{i t}=\eta_{i}+\gamma \omega_{i t-1}+e_{2, i t}=\frac{\eta_{i}}{1-\gamma}+\sum_{j=1}^{\infty} \gamma^{j} e_{2, i t-j} .
$$

In the above expression, TFP is a simple sum of the persistent component $b_{i}=\eta_{i} /(1-\gamma)$ and the transient component $a_{i t}=\sum_{j=1}^{\infty} \gamma^{j} e_{2, i t-j}$. 
In fact, under the linear TFP specification above, our CFE-FE estimator is equivalent to the dynamic panel estimators developed in Blundell and Bond $(1998,2000)$, which apply sets of predetermined instruments to

$$
v a_{i t}=\eta_{i}+\gamma v a_{i t-1}+\left(l_{i t}-\gamma l_{i t-1}\right) \beta_{l}+\left(k_{i t}-\gamma k_{i t-1}\right) \beta_{k}+\xi_{i t}
$$

with $\xi_{i t}=\left(u_{i t}-\gamma u_{i t-1}\right)+e_{2, i t}$. Both the CFE-FE and dynamic panel estimators such as those in Blundell and Bond $(1998,2000)$ will yield the same results when they share the same initial conditions under equation (14) and the conditions in Lee (2014). However, this equivalence will only hold when $E\left[\omega_{i t} \mid \omega_{i t-1}, \eta_{i}\right]$ is linear as in equation (14). When $E\left[\omega_{i t} \mid \omega_{i t-1}, \eta_{i}\right]$ is nonlinear, the dynamic panel approach will result in inconsistent estimates. Since our approach is nonparametric in $E\left[\omega_{i t} \mid \omega_{i t-1}, \eta_{i}\right]$, similar to the original CFE-OP, it will yield consistent estimates even under nonlinear Markov dynamics in $\omega_{i t}$.

As an illustration, consider $E\left[\omega_{i t} \mid \omega_{i t-1}, \eta_{i}\right]=\eta_{i}+\gamma_{1} \omega_{i t-1}+\gamma_{2} \omega_{i t-1}^{2}$. Though $E\left[\omega_{i t} \mid \omega_{i t-1}\right.$, $\left.\eta_{i}\right]$ is still linear in parameters, this quadratic specification cannot be fully controlled in the dynamic panel regression above, hence the regression error term becomes $\xi_{i t}=\gamma_{2} \omega_{i t-1}^{2}+$ $\left(u_{i t}-\gamma_{1} u_{i t-1}\right)+e_{2, i t}$. Then, since $\omega_{i t-1}^{2}$ can be correlated with $v a_{i t-1}, l_{i t-1}$, or $k_{i t-1}$, the dynamic panel estimators will not be consistent without more exogenous instruments.

\section{Empirical results}

In this section, we apply a selection of existing CFEs to two datasets popular in the firm productivity literature, and show that they fail to account for persistence in firm productivity, relegating part of it to the error term. We also demonstrate that our estimator absorbs much of this persistence, thus reducing the potential transmission bias that cannot be controlled by conventional CFEs. We report the results from both value added and gross output specifications of the production function.

\section{Data}

The first dataset comes from Instituto Nacional de Estadistica and covers all Chilean manufacturing plants with more than 10 employees during the years between 1979 and 1996. These data have been used in many studies of firm-level productivity, including Levinsohn and Petrin (2003), Gandhi, Navarro and Rivers (2011), and Ackerberg et al. (2015), as well as in applications of productivity analysis in other contexts, most notably Pavcnik (2002), Kasahara and Rodrigue (2008), and Petrin and Levinsohn (2013). For each of the 10,927 plants in our sample, the data include the four-digit ISIC industry code identifier, gross output, material inputs, capital stock and investments, and labour input measured in person-years, converted where necessary into real values using industry price deflators. A more detailed description of the data is available in Levinsohn and Petrin (2003).

The second dataset comes from the Danish Business Statistics Register, maintained by Statistics Denmark, and includes all firms registered in Denmark. In this study we use information on manufacturing firms for the years 1995-2007. The variables observed in each year include the four-digit NACE industry identifier, total output, value added, fixed assets, investments, material inputs, and employment (headcount measure). Lentz 
and Mortensen (2008), Munch and Skaksen (2008), Stoyanov and Zubanov (2012), and De Loecker and Warzynski (2012) used these data.

\section{Estimation results}

Tables 1 and 2 present the OLS and the standard control function estimation results of the production function for Chile and Denmark, respectively. In each table, the column 'OLS' shows the linear regression results of equation (1); the column 'OLS-FE' shows the estimation results of linear regression of equation (1) with firm fixed effect (i.e. the withingroup estimator); the column 'OP' shows the standard control function estimation results of Olley and Pakes (1996) or Levinsohn and Petrin (2003); and the column 'OPW' shows the results from the Wooldridge (2009) estimator. ${ }^{5}$ The rest of the columns present the OPW results for the three largest manufacturing industries in each country. The standard errors in all specifications are estimated from the residuals clustered at the firm level.

Tables 1 and 2 also report the first-order autoregressive coefficient estimates of the regression residuals, $\rho_{1}$ for the first-stage regression residuals ( $e_{1}$ in the text), and $\rho_{2}$ for the second-stage regression residuals $\left(e_{2}\right)$. We estimate the first-stage residuals as the error term from the first-stage equation (4), and compute the second-stage residuals $e_{2, i t}$ as the difference between the total residuals from equation (7) and the first-stage residuals. Although our estimates of the residuals are imperfect because of the presence of approximation errors, the residual autocorrelation coefficients calculated from them, which are probably attenuated by the approximation error, are still informative.

Tables 1 and 2 show that the overall residual autocorrelation coefficient $\rho$ in the OLS and OP regressions without fixed effects is above 0.5 . Furthermore, as seen in the correlogram in Figure 3, the high residual autocorrelation hardly declines with time. An interesting case is the OLS regression with fixed effects in column 'OLS-FE', where the residual autocorrelation is much lower: 0.088 for the Danish and 0.241 for the Chilean samples. The comparison between the regressions with and without firm fixed effects, as well as the stability of the residual autocorrelation over time, hints at the presence of a persistent firm-specific intercept in TFP.

The coefficients $\rho_{1}, \rho_{2}$ reveal strong autocorrelation in the first-stage and a weaker but still considerable autocorrelation in the second-stage residuals. High values of $\rho_{1}$, 0.54 and above, imply the presence of a persistent component in TFP that the control function has not captured, which is in breach of the scalar unobservability Assumption 3. Significant autocorrelation in the second-stage residuals implies the presence of a firmspecific intercept in the TFP process, contradicting Assumption 4. Thus, the estimation results so far suggest that a CFE with firm fixed effects in the control function and in the TFP process may be required.

Another potential source of persistence in the CFE residuals may be a higher-order Markov process in TFP - a threat to the consistency of CFE other than a firm-specific persistent TFP component. The presence of a higher-order Markov process in productivity can be examined and addressed by extending the existing CFEs to allow for a second-order Markov process,

\footnotetext{
${ }^{5}$ We use the Stata command ivreg2 for Wooldridge (2009) and our estimators.
} 
TABLE 1

Production function estimation results from existing estimators, Chile

\begin{tabular}{|c|c|c|c|c|c|c|c|}
\hline & $(1)$ & $(2)$ & (3) & (4) & (5) & $(6)$ & (7) \\
\hline Estimator & OLS & OLS-FE & $\mathrm{OP}$ & OPW & OPW & OPW & OPW \\
\hline \multirow[t]{3}{*}{ Industry sample } & \multirow{2}{*}{\multicolumn{4}{|c|}{ All manufacturing industries }} & $\begin{array}{c}\text { Food } \\
\text { products }\end{array}$ & $\begin{array}{c}\text { Fabricated } \\
\text { metals }\end{array}$ & Textiles \\
\hline & & & & & (311) & (381) & $(321)$ \\
\hline & \multicolumn{7}{|c|}{ Dependent variable: $\log$ value added } \\
\hline Labor & $\begin{array}{c}1.023 \\
(0.018)\end{array}$ & $\begin{array}{c}0.813 \\
(0.016)\end{array}$ & $\begin{array}{c}0.689 \\
(0.017)\end{array}$ & $\begin{array}{c}0.758 \\
(0.017)\end{array}$ & $\begin{array}{c}0.582 \\
(0.027)\end{array}$ & $\begin{array}{c}0.795 \\
(0.045)\end{array}$ & $\begin{array}{c}0.623 \\
(0.047)\end{array}$ \\
\hline Capital & $\begin{array}{c}0.308 \\
(0.010)\end{array}$ & $\begin{array}{c}0.128 \\
(0.009)\end{array}$ & $\begin{array}{c}0.387 \\
(0.018)\end{array}$ & $\begin{array}{c}0.349 \\
(0.018)\end{array}$ & $\begin{array}{c}0.321 \\
(0.035)\end{array}$ & $\begin{array}{c}0.221 \\
(0.056)\end{array}$ & $\begin{array}{c}0.259 \\
(0.048)\end{array}$ \\
\hline $\mathrm{N}$ & 54,801 & 54,801 & 49,228 & 49,265 & 14,823 & 4,171 & 4,189 \\
\hline$\rho$ & $\begin{array}{c}0.696 \\
(0.003)\end{array}$ & $\begin{array}{c}0.264 \\
(0.007)\end{array}$ & $\begin{array}{c}0.644 \\
(0.007)\end{array}$ & $\begin{array}{c}0.647 \\
(0.007)\end{array}$ & $\begin{array}{c}0.491 \\
(0.014)\end{array}$ & $\begin{array}{c}0.569 \\
(0.025)\end{array}$ & $\begin{array}{c}0.576 \\
(0.024)\end{array}$ \\
\hline$\rho_{1}$ & & & $\begin{array}{c}0.625 \\
(0.006)\end{array}$ & $\begin{array}{c}0.637 \\
(0.007)\end{array}$ & $\begin{array}{c}0.496 \\
(0.014)\end{array}$ & $\begin{array}{c}0.535 \\
(0.024)\end{array}$ & $\begin{array}{c}0.540 \\
(0.023)\end{array}$ \\
\hline \multirow[t]{2}{*}{$\rho_{2}$} & & & $\begin{array}{l}-0.222 \\
(0.008) \\
\end{array}$ & $\begin{array}{c}-0.042 \\
(0.016) \\
\end{array}$ & $\begin{array}{c}0.155 \\
(0.020) \\
\end{array}$ & $\begin{array}{l}-0.046 \\
(0.074) \\
\end{array}$ & $\begin{array}{c}0.171 \\
(0.029)\end{array}$ \\
\hline & \multicolumn{7}{|c|}{ The share of between-firm variation in residuals } \\
\hline$e_{1}$ & 0.57 & $\mathrm{n} / \mathrm{a}$ & 0.51 & 0.53 & 0.37 & 0.47 & 0.46 \\
\hline \multirow[t]{2}{*}{$e_{2}$} & & & 0.16 & 0.19 & 0.11 & 0.24 & 0.11 \\
\hline & \multicolumn{7}{|c|}{ Dependent variable: log output } \\
\hline Labor & $\begin{array}{c}0.301 \\
(0.008)\end{array}$ & $\begin{array}{c}0.285 \\
(0.008)\end{array}$ & $\begin{array}{c}0.246 \\
(0.010)\end{array}$ & $\begin{array}{c}0.243 \\
(0.009)\end{array}$ & $\begin{array}{c}0.159 \\
(0.011)\end{array}$ & $\begin{array}{c}0.286 \\
(0.025)\end{array}$ & $\begin{array}{c}0.233 \\
(0.021)\end{array}$ \\
\hline Capital & $\begin{array}{c}0.088 \\
(0.004)\end{array}$ & $\begin{array}{c}0.044 \\
(0.004)\end{array}$ & $\begin{array}{c}0.198 \\
(0.045)\end{array}$ & $\begin{array}{c}0.113 \\
(0.009)\end{array}$ & $\begin{array}{c}0.057 \\
(0.015)\end{array}$ & $\begin{array}{c}0.111 \\
(0.030)\end{array}$ & $\begin{array}{c}0.087 \\
(0.023)\end{array}$ \\
\hline Materials & $\begin{array}{c}0.722 \\
(0.005)\end{array}$ & $\begin{array}{c}0.645 \\
(0.007)\end{array}$ & $\begin{array}{c}0.714 \\
(0.007)\end{array}$ & $\begin{array}{c}0.740 \\
(0.006)\end{array}$ & $\begin{array}{c}0.866 \\
(0.008)\end{array}$ & $\begin{array}{c}0.687 \\
(0.019)\end{array}$ & $\begin{array}{c}0.766 \\
(0.015)\end{array}$ \\
\hline $\mathrm{N}$ & 54,857 & 54,801 & 49,228 & 49,265 & 14,823 & 4,171 & 4,189 \\
\hline$\rho$ & $\begin{array}{c}0.644 \\
(0.003)\end{array}$ & $\begin{array}{c}0.241 \\
(0.008)\end{array}$ & $\begin{array}{c}0.708 \\
(0.006)\end{array}$ & $\begin{array}{c}0.702 \\
(0.013)\end{array}$ & $\begin{array}{c}0.570 \\
(0.032)\end{array}$ & $\begin{array}{c}0.620 \\
(0.028)\end{array}$ & $\begin{array}{c}0.577 \\
(0.032)\end{array}$ \\
\hline$\rho_{1}$ & & & $\begin{array}{c}0.679 \\
(0.012)\end{array}$ & $\begin{array}{c}0.705 \\
(0.015)\end{array}$ & $\begin{array}{c}0.539 \\
(0.037)\end{array}$ & $\begin{array}{c}0.648 \\
(0.031)\end{array}$ & $\begin{array}{c}0.547 \\
(0.039)\end{array}$ \\
\hline \multirow[t]{2}{*}{$\rho_{2}$} & & & $\begin{array}{l}-0.275 \\
(0.013)\end{array}$ & $\begin{array}{c}0.136 \\
(0.016)\end{array}$ & $\begin{array}{c}0.344 \\
(0.037)\end{array}$ & $\begin{array}{c}0.376 \\
(0.073)\end{array}$ & $\begin{array}{c}0.102 \\
(0.065)\end{array}$ \\
\hline & \multicolumn{7}{|c|}{ The share of between-firm variation in residuals } \\
\hline$e_{1}$ & 0.53 & $\mathrm{n} / \mathrm{a}$ & 0.60 & 0.64 & 0.48 & 0.56 & 0.54 \\
\hline$e_{2}$ & & & 0.21 & 0.35 & 0.58 & 0.38 & 0.34 \\
\hline
\end{tabular}

Notes: Standard errors in parentheses are clustered by firm. OPW stands for the Wooldridge (2009) modification of the OP estimator. For OP and OPW estimators, the share of between-firm variation in residuals is calculated for the first-stage regression. 
TABLE 2

Production function estimation results from existing estimators, Denmark

\begin{tabular}{|c|c|c|c|c|c|c|c|}
\hline & (1) & (2) & (3) & (4) & (5) & (6) & (7) \\
\hline Estimator & OLS & OLS-FE & OP & OPW & OPW & OPW & OPW \\
\hline \multirow[t]{2}{*}{ Industry sample } & \multicolumn{4}{|c|}{ All manufacturing industries } & $\begin{array}{c}\text { Fabricated } \\
\text { metals }\end{array}$ & Printing & $\begin{array}{c}\text { Food } \\
\text { products }\end{array}$ \\
\hline & \multicolumn{7}{|c|}{ Dependent variable: log value added } \\
\hline Labor & $\begin{array}{c}0.917 \\
(0.004)\end{array}$ & $\begin{array}{c}0.723 \\
(0.003)\end{array}$ & $\begin{array}{c}0.631 \\
(0.006)\end{array}$ & $\begin{array}{c}0.658 \\
(0.005)\end{array}$ & $\begin{array}{c}0.724 \\
(0.010)\end{array}$ & $\begin{array}{c}0.686 \\
(0.014)\end{array}$ & $\begin{array}{c}0.655 \\
(0.012)\end{array}$ \\
\hline Capital & $\begin{array}{c}0.139 \\
(0.003)\end{array}$ & $\begin{array}{c}0.108 \\
(0.003)\end{array}$ & $\begin{array}{c}0.203 \\
(0.002)\end{array}$ & $\begin{array}{c}0.102 \\
(0.003)\end{array}$ & $\begin{array}{c}0.094 \\
(0.005)\end{array}$ & $\begin{array}{c}0.079 \\
(0.007)\end{array}$ & $\begin{array}{c}0.105 \\
(0.008)\end{array}$ \\
\hline $\mathrm{N}$ & 151,556 & 151,556 & 122,938 & 122,902 & 24,235 & 15,061 & 14,890 \\
\hline$\rho$ & $\begin{array}{c}0.777 \\
(0.002)\end{array}$ & $\begin{array}{c}0.136 \\
(0.008)\end{array}$ & $\begin{array}{c}0.648 \\
(0.007)\end{array}$ & $\begin{array}{c}0.554 \\
(0.008)\end{array}$ & $\begin{array}{c}0.528 \\
(0.015)\end{array}$ & $\begin{array}{c}0.554 \\
(0.019)\end{array}$ & $\begin{array}{c}0.535 \\
(0.031)\end{array}$ \\
\hline$\rho_{1}$ & & & $\begin{array}{c}0.559 \\
(0.006)\end{array}$ & $\begin{array}{c}0.582 \\
(0.007)\end{array}$ & $\begin{array}{c}0.550 \\
(0.015)\end{array}$ & $\begin{array}{c}0.554 \\
(0.015)\end{array}$ & $\begin{array}{c}0.541 \\
(0.022)\end{array}$ \\
\hline \multirow[t]{2}{*}{$\rho_{2}$} & & & $\begin{array}{c}-0.143 \\
(0.005) \\
\end{array}$ & $\begin{array}{l}-0.212 \\
(0.007) \\
\end{array}$ & $\begin{array}{c}-0.163 \\
(0.014) \\
\end{array}$ & $\begin{array}{l}-0.180 \\
(0.028) \\
\end{array}$ & $\begin{array}{c}-0.164 \\
(0.020) \\
\end{array}$ \\
\hline & \multicolumn{7}{|c|}{ The share of between-firm variation in residuals } \\
\hline$e_{1}$ & 0.75 & $\mathrm{n} / \mathrm{a}$ & 0.56 & 0.56 & 0.51 & 0.55 & 0.52 \\
\hline \multirow[t]{2}{*}{$\underline{e_{2}}$} & & & 0.26 & 0.21 & 0.32 & 0.20 & 0.29 \\
\hline & \multicolumn{7}{|c|}{ Dependent variable: log output } \\
\hline Labor & $\begin{array}{c}0.436 \\
(0.006)\end{array}$ & $\begin{array}{c}0.476 \\
(0.002)\end{array}$ & $\begin{array}{c}0.425 \\
(0.006)\end{array}$ & $\begin{array}{c}0.352 \\
(0.005)\end{array}$ & $\begin{array}{c}0.441 \\
(0.009)\end{array}$ & $\begin{array}{c}0.478 \\
(0.015)\end{array}$ & $\begin{array}{c}0.312 \\
(0.006)\end{array}$ \\
\hline Capital & $\begin{array}{c}0.055 \\
(0.002)\end{array}$ & $\begin{array}{c}0.059 \\
(0.002)\end{array}$ & $\begin{array}{c}0.031 \\
(0.001)\end{array}$ & $\begin{array}{c}0.019 \\
(0.002)\end{array}$ & $\begin{array}{c}0.025 \\
(0.003)\end{array}$ & $\begin{array}{c}0.017 \\
(0.005)\end{array}$ & $\begin{array}{c}0.019 \\
(0.004)\end{array}$ \\
\hline Materials & $\begin{array}{c}0.527 \\
(0.005)\end{array}$ & $\begin{array}{c}0.388 \\
(0.008)\end{array}$ & $\begin{array}{c}0.521 \\
(0.005)\end{array}$ & $\begin{array}{c}0.601 \\
(0.004)\end{array}$ & $\begin{array}{c}0.516 \\
(0.008)\end{array}$ & $\begin{array}{c}0.542 \\
(0.012)\end{array}$ & $\begin{array}{c}0.682 \\
(0.005)\end{array}$ \\
\hline $\mathrm{N}$ & 151,504 & 151,504 & 123,082 & 123,082 & 23,880 & 15,027 & 14,887 \\
\hline$\rho$ & $\begin{array}{c}0.593 \\
(0.003)\end{array}$ & $\begin{array}{c}0.088 \\
(0.011)\end{array}$ & $\begin{array}{c}0.581 \\
(0.008)\end{array}$ & $\begin{array}{c}0.559 \\
(0.009)\end{array}$ & $\begin{array}{c}0.577 \\
(0.018)\end{array}$ & $\begin{array}{c}0.496 \\
(0.021)\end{array}$ & $\begin{array}{c}0.555 \\
(0.023)\end{array}$ \\
\hline$\rho_{1}$ & & & $\begin{array}{c}0.572 \\
(0.007)\end{array}$ & $\begin{array}{c}0.566 \\
(0.008)\end{array}$ & $\begin{array}{c}0.580 \\
(0.017)\end{array}$ & $\begin{array}{c}0.534 \\
(0.017)\end{array}$ & $\begin{array}{c}0.553 \\
(0.023)\end{array}$ \\
\hline \multirow[t]{2}{*}{$\rho_{2}$} & & & $\begin{array}{l}-0.206 \\
(0.005) \\
\end{array}$ & $\begin{array}{l}-0.184 \\
(0.005) \\
\end{array}$ & $\begin{array}{l}-0.167 \\
(0.014) \\
\end{array}$ & $\begin{array}{c}-0.088 \\
(0.018) \\
\end{array}$ & $\begin{array}{l}-0.185 \\
(0.015) \\
\end{array}$ \\
\hline & \multicolumn{7}{|c|}{ The share of between-firm variation in residuals } \\
\hline$e_{1}$ & 0.57 & $\mathrm{n} / \mathrm{a}$ & 0.56 & 0.54 & 0.55 & 0.51 & 0.47 \\
\hline$e_{2}$ & & & 0.24 & 0.29 & 0.31 & 0.25 & 0.24 \\
\hline
\end{tabular}

Notes: Standard errors in parentheses are clustered by firm. OPW stands for the Wooldridge (2009) modification of the OP estimator. For OP and OPW estimators, the share of between-firm variation in residuals is calculated for the first-stage regression. 


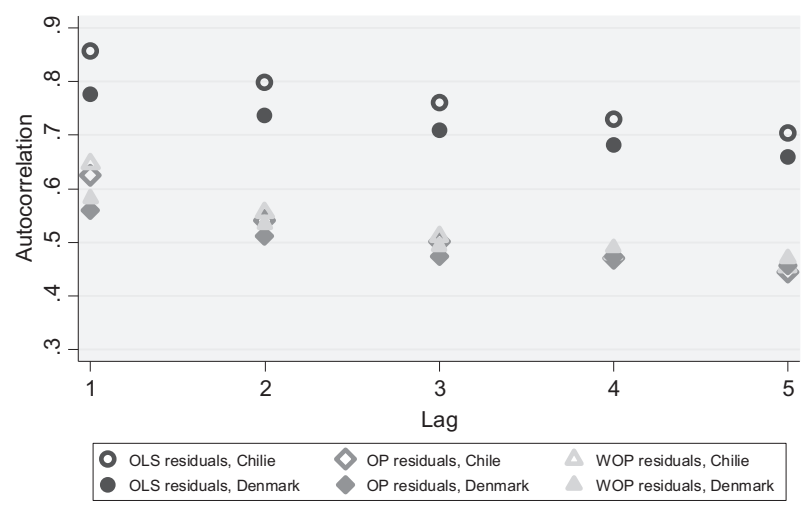

Figure 3. Autocorrelation correlogram for the regression residuals Note: Total residuals are used for OLS; first-stage residuals for OP and WOP

$$
\omega_{i t}=\mathrm{E}\left[\omega_{i t} \mid \omega_{i t-1}, \omega_{i t-2}\right]+e_{2, i t},
$$

at the cost of extra assumptions on the control function and at least one additional proxy variable, besides materials, to separately identify the two lags of $\omega_{i t}$ (Ackerberg et al., 2007; Stoyanov and Zubanov, 2014). We implement the estimator proposed in these studies by choosing capital investment as the additional proxy.

TABLE 3

Estimation results from the benchmark OP with a second-order Markov process in TFP

\begin{tabular}{|c|c|c|c|c|c|c|c|c|}
\hline & (1) & (2) & (3) & (4) & (5) & (6) & (7) & (8) \\
\hline & \multicolumn{4}{|c|}{ Chile } & \multicolumn{4}{|c|}{ Denmark } \\
\hline & All & $\begin{array}{c}\text { Food } \\
\text { products } \\
(311)\end{array}$ & $\begin{array}{c}\text { Fabricated } \\
\text { metals } \\
(381)\end{array}$ & $\begin{array}{c}\text { Textiles } \\
\text { (321) }\end{array}$ & All & $\begin{array}{c}\text { Fabricated } \\
\text { metals } \\
(28)\end{array}$ & $\begin{array}{c}\text { Printing } \\
(22)\end{array}$ & $\begin{array}{c}\text { Food } \\
\text { products } \\
(15)\end{array}$ \\
\hline Labor & $\begin{array}{c}0.504 \\
(0.010)\end{array}$ & $\begin{array}{c}0.425 \\
(0.020)\end{array}$ & $\begin{array}{c}0.594 \\
(0.029)\end{array}$ & $\begin{array}{c}0.527 \\
(0.031)\end{array}$ & $\begin{array}{c}0.683 \\
(0.006)\end{array}$ & $\begin{array}{c}0.738 \\
(0.012)\end{array}$ & $\begin{array}{c}0.714 \\
(0.017)\end{array}$ & $\begin{array}{c}0.656 \\
(0.013)\end{array}$ \\
\hline Capital & $\begin{array}{c}0.366 \\
(0.022)\end{array}$ & $\begin{array}{c}0.314 \\
(0.045)\end{array}$ & $\begin{array}{c}0.442 \\
(0.067)\end{array}$ & $\begin{array}{c}0.231 \\
(0.058)\end{array}$ & $\begin{array}{c}0.080 \\
(0.003)\end{array}$ & $\begin{array}{c}0.069 \\
(0.006)\end{array}$ & $\begin{array}{c}0.066 \\
(0.007)\end{array}$ & $\begin{array}{c}0.093 \\
(0.008)\end{array}$ \\
\hline $\mathrm{N}$ & 16,081 & 4,127 & 1,503 & 1,261 & 83,948 & 16,604 & 10,080 & 9,857 \\
\hline$\rho$ & $\begin{array}{c}0.730 \\
(0.011)\end{array}$ & $\begin{array}{c}0.553 \\
(0.025)\end{array}$ & $\begin{array}{c}0.356 \\
(0.058)\end{array}$ & $\begin{array}{c}0.588 \\
(0.040)\end{array}$ & $\begin{array}{c}0.577 \\
(0.008)\end{array}$ & $\begin{array}{c}0.554 \\
(0.016)\end{array}$ & $\begin{array}{c}0.579 \\
(0.020)\end{array}$ & $\begin{array}{c}0.534 \\
(0.025)\end{array}$ \\
\hline$\rho_{1}$ & $\begin{array}{c}0.707 \\
(0.012)\end{array}$ & $\begin{array}{c}0.519 \\
(0.028)\end{array}$ & $\begin{array}{c}0.616 \\
(0.033)\end{array}$ & $\begin{array}{c}0.589 \\
(0.041)\end{array}$ & $\begin{array}{c}0.575 \\
(0.008)\end{array}$ & $\begin{array}{c}0.553 \\
(0.017)\end{array}$ & $\begin{array}{c}0.577 \\
(0.018)\end{array}$ & $\begin{array}{c}0.558 \\
(0.024)\end{array}$ \\
\hline$\rho_{2}$ & $\begin{array}{l}-0.066 \\
(0.016)\end{array}$ & $\begin{array}{l}-0.173 \\
(0.019)\end{array}$ & $\begin{array}{l}-0.026 \\
(0.088)\end{array}$ & $\begin{array}{l}-0.051 \\
(0.030)\end{array}$ & $\begin{array}{l}-0.125 \\
(0.012)\end{array}$ & $\begin{array}{l}-0.164 \\
(0.019)\end{array}$ & $\begin{array}{l}-0.058 \\
(0.020)\end{array}$ & $\begin{array}{l}-0.117 \\
(0.027)\end{array}$ \\
\hline & \multicolumn{8}{|c|}{ The share of between-firm variation in residuals } \\
\hline$e_{1}$ & 0.63 & 0.47 & 0.56 & 0.55 & 0.55 & 0.51 & 0.53 & 0.54 \\
\hline$e_{2}$ & 0.17 & 0.10 & 0.26 & 0.17 & 0.24 & 0.19 & 0.28 & 0.26 \\
\hline
\end{tabular}

Notes: Standard errors in parentheses are clustered by firm.

Table 3 reports the regression estimates and residual autocorrelations for the value added specification with firm productivity following a second-order Markov process without 
TABLE 4

CFE-FE production function estimation results

\begin{tabular}{|c|c|c|c|c|c|c|c|c|}
\hline & (1) & (2) & (3) & (4) & (5) & $(6)$ & (7) & $(8)$ \\
\hline & \multicolumn{4}{|c|}{ Chile } & \multicolumn{4}{|c|}{ Denmark } \\
\hline & $\begin{array}{c}\text { All } \\
\text { industries }\end{array}$ & $\begin{array}{c}\text { Food } \\
\text { products } \\
(311)\end{array}$ & $\begin{array}{c}\text { Fabricated } \\
\text { metals } \\
(381)\end{array}$ & $\begin{array}{c}\text { Textiles } \\
\text { (321) }\end{array}$ & $\begin{array}{c}\text { All } \\
\text { industries }\end{array}$ & $\begin{array}{c}\text { Fabricated } \\
\text { metals } \\
(28)\end{array}$ & $\begin{array}{c}\text { Printing } \\
(22)\end{array}$ & $\begin{array}{c}\text { Food } \\
\text { products } \\
(15)\end{array}$ \\
\hline & \multicolumn{8}{|c|}{ Dependent variable: log value added } \\
\hline Labor & $\begin{array}{c}0.744 \\
(0.097)\end{array}$ & $\begin{array}{c}0.779 \\
(0.180)\end{array}$ & $\begin{array}{c}0.614 \\
(0.270)\end{array}$ & $\begin{array}{c}0.858 \\
(0.308)\end{array}$ & $\begin{array}{c}0.838 \\
(0.220)\end{array}$ & $\begin{array}{c}0.815 \\
(0.225)\end{array}$ & $\begin{array}{c}0.765 \\
(0.206)\end{array}$ & $\begin{array}{c}0.877 \\
(0.128)\end{array}$ \\
\hline Capital & $\begin{array}{c}0.115 \\
(0.018)\end{array}$ & $\begin{array}{c}0.095 \\
(0.033)\end{array}$ & $\begin{array}{c}0.190 \\
(0.062)\end{array}$ & $\begin{array}{c}0.051 \\
(0.045)\end{array}$ & $\begin{array}{c}0.106 \\
(0.015)\end{array}$ & $\begin{array}{c}0.074 \\
(0.038)\end{array}$ & $\begin{array}{c}0.090 \\
(0.013)\end{array}$ & $\begin{array}{c}0.103 \\
(0.013)\end{array}$ \\
\hline $\mathrm{N}$ & 44,028 & 13,311 & 3,716 & 3,749 & 101,149 & 19,985 & 12,282 & 12,088 \\
\hline$\rho$ & $\begin{array}{c}0.251 \\
(0.012)\end{array}$ & $\begin{array}{c}0.254 \\
(0.021)\end{array}$ & $\begin{array}{c}0.225 \\
(0.037)\end{array}$ & $\begin{array}{c}0.165 \\
(0.041)\end{array}$ & $\begin{array}{c}0.099 \\
(0.021)\end{array}$ & $\begin{array}{c}0.055 \\
(0.031)\end{array}$ & $\begin{array}{c}0.004 \\
(0.044)\end{array}$ & $\begin{array}{c}0.202 \\
(0.051)\end{array}$ \\
\hline$\rho_{1}$ & $\begin{array}{c}0.178 \\
(0.016)\end{array}$ & $\begin{array}{c}0.186 \\
(0.046)\end{array}$ & $\begin{array}{c}0.124 \\
(0.042)\end{array}$ & $\begin{array}{c}0.131 \\
(0.109)\end{array}$ & $\begin{array}{c}0.108 \\
(0.036)\end{array}$ & $\begin{array}{c}0.139 \\
(0.051)\end{array}$ & $\begin{array}{c}0.045 \\
(0.034)\end{array}$ & $\begin{array}{c}0.095 \\
(0.045)\end{array}$ \\
\hline$\rho_{2}$ & $\begin{array}{c}0.336 \\
(0.024)\end{array}$ & $\begin{array}{c}0.347 \\
(0.049)\end{array}$ & $\begin{array}{c}0.057 \\
(0.047)\end{array}$ & $\begin{array}{c}0.237 \\
(0.168)\end{array}$ & $\begin{array}{c}-0.151 \\
(0.074)\end{array}$ & $\begin{array}{c}0.165 \\
(0.065)\end{array}$ & $\begin{array}{c}0.073 \\
(0.060)\end{array}$ & $\begin{array}{c}0.046 \\
(0.052)\end{array}$ \\
\hline & \multicolumn{8}{|c|}{ Dependent variable: log output } \\
\hline Labor & $\begin{array}{c}0.103 \\
(0.199)\end{array}$ & $\begin{array}{c}0.071 \\
(0.198)\end{array}$ & $\begin{array}{c}0.248 \\
(0.060)\end{array}$ & $\begin{array}{c}0.133 \\
(0.389)\end{array}$ & $\begin{array}{c}0.347 \\
(0.005)\end{array}$ & $\begin{array}{c}0.441 \\
(0.000)\end{array}$ & $\begin{array}{c}0.558 \\
(-0.080)\end{array}$ & $\begin{array}{c}0.353 \\
(-0.041)\end{array}$ \\
\hline Capital & $\begin{array}{c}0.049 \\
(0.011)\end{array}$ & $\begin{array}{c}0.044 \\
(0.020)\end{array}$ & $\begin{array}{c}0.141 \\
(0.104)\end{array}$ & $\begin{array}{c}0.027 \\
(0.037)\end{array}$ & $\begin{array}{c}0.063 \\
(0.005)\end{array}$ & $\begin{array}{c}0.044 \\
(0.008)\end{array}$ & $\begin{array}{c}0.053 \\
(0.011)\end{array}$ & $\begin{array}{c}0.035 \\
(0.017)\end{array}$ \\
\hline Materials & $\begin{array}{c}0.680 \\
(0.057)\end{array}$ & $\begin{array}{c}0.762 \\
(0.075)\end{array}$ & $\begin{array}{c}0.702 \\
(0.260)\end{array}$ & $\begin{array}{c}0.775 \\
(0.199)\end{array}$ & $\begin{array}{c}0.466 \\
(0.026)\end{array}$ & $\begin{array}{c}0.471 \\
(0.041)\end{array}$ & $\begin{array}{c}0.356 \\
(0.037)\end{array}$ & $\begin{array}{c}0.574 \\
(0.115)\end{array}$ \\
\hline $\mathrm{N}$ & 17,683 & 4,559 & 1,647 & 1,392 & 101,377 & 20,028 & 12,298 & 12,107 \\
\hline$\rho$ & $\begin{array}{c}0.238 \\
(0.021)\end{array}$ & $\begin{array}{c}0.237 \\
(0.045)\end{array}$ & $\begin{array}{c}0.041 \\
(0.067)\end{array}$ & $\begin{array}{c}0.121 \\
(0.077)\end{array}$ & $\begin{array}{c}0.154 \\
(0.014)\end{array}$ & $\begin{array}{c}0.069 \\
(0.028)\end{array}$ & $\begin{array}{c}0.080 \\
(0.043)\end{array}$ & $\begin{array}{c}0.169 \\
(0.081)\end{array}$ \\
\hline$\rho_{1}$ & $\begin{array}{c}0.191 \\
(0.020)\end{array}$ & $\begin{array}{l}-0.033 \\
(0.064)\end{array}$ & $\begin{array}{c}0.187 \\
(0.082)\end{array}$ & $\begin{array}{c}0.090 \\
(0.054)\end{array}$ & $\begin{array}{c}0.108 \\
(0.014)\end{array}$ & $\begin{array}{c}0.047 \\
(0.026)\end{array}$ & $\begin{array}{c}0.029 \\
(0.034)\end{array}$ & $\begin{array}{c}0.091 \\
(0.055)\end{array}$ \\
\hline$\rho_{2}$ & $\begin{array}{c}-0.051 \\
(0.029)\end{array}$ & $\begin{array}{l}-0.046 \\
(0.066)\end{array}$ & $\begin{array}{c}0.171 \\
(0.083)\end{array}$ & $\begin{array}{c}0.247 \\
(0.056)\end{array}$ & $\begin{array}{c}0.015 \\
(0.015)\end{array}$ & $\begin{array}{l}-0.015 \\
(0.057)\end{array}$ & $\begin{array}{l}-0.089 \\
(0.030)\end{array}$ & $\begin{array}{c}-0.114 \\
(0.049)\end{array}$ \\
\hline
\end{tabular}

Notes: Standard errors in parentheses are clustered by firm.

firm fixed effects. This modification produces second-stage residuals $e_{2, i t}$ that are less strongly autocorrelated than those from the standard CFE. However, the first-stage residual autocorrelation is essentially unaffected in both the Chilean and Danish samples, implying that omitted higher-order Markov terms are unlikely to be an important factor contributing to the residual persistence. Its most likely source remains the presence of a firm-specific intercept in TFP, which our estimator is capable of addressing.

Table 4 shows the factor input elasticity estimates from the CFE-FE for the Chilean and Danish samples. The table also reports the first-order autoregression coefficient estimates of the first- and second-stage regression residuals, $\rho_{1}$ and $\rho_{2}$, as in Tables 1 and $2{ }^{6}$

\footnotetext{
${ }^{6}$ Since the CFE estimator only produces the changes in the first- and second-stage residuals, the point estimates and standard errors of $\rho_{1}$ and $\rho_{2}$ are recovered from the regressions of $\Delta e_{1, i t}$ on $\Delta e_{1, i t-1}$ and of $\Delta e_{2, i t}$ on $\Delta e_{2, i t-1}$ using the Delta method.
} 
The results in Table 4 support the argument for controlling for firm fixed effects in productivity by showing a considerable reduction in the magnitude of the residual autocorrelation coefficients as compared to the standard CFE estimates in Tables 1 and 2: a range of $0.041-0.254$ for Chile and $0.004-0.169$ for Denmark in the CFE specifications vs. $0.5-0.6$ without. The omitted factors which were the sources of residual autocorrelation do not seem to be random components in the error terms $e_{1, i t}$ or $e_{2, i t}$ since the input elasticity estimates change as well once the fixed effects are introduced.

The changes in the input elasticity estimates reflect correlations between persistent TFP heterogeneity, omitted in the conventional CFEs, and factor inputs. For example, in the gross output specification estimated on the Danish sample, the capital input elasticity estimate goes up by two-thirds and the estimates of the labour and material coefficients go down by one-fourth, or by 10 standard errors. In the value added specification, the coefficient on labour goes up while the coefficient on capital decreases.

The differences in factor input elasticities between the CFE-FE and conventional CFE estimators do not form any systematic pattern, suggesting that the correlation between factor input choices and firm unobservables, for which our estimator controls, are specific to industries and countries. The benefit of using our estimator vs. other estimators is not in that it produces more 'intuitive' estimates but in that it can better control for persistent heterogeneity and thus better handle the transmission bias.

\section{Conclusions}

In this paper, we have identified a potential transmission bias in the production function estimators based on the control function approach. This bias occurs because the control function does not fully capture productivity persistence. In particular, this happens when productivity follows a dynamic process with a firm-specific effect. We show that this case can be dealt with by introducing firm fixed effects in the control function and derive a consistent estimator, the CFE-FE. We also extend the CFE-FE framework to address the case when investment (or materials) responds differently to transient and persistent productivity components, and show that CFE-FE is consistent under the assumptions we outline.

We show our estimator in action by reporting a substantial firm-specific component in the regression residuals estimated from data on Chilean and Danish manufacturing firms. The presence of this component is a marker of transmission bias, since a correctly specified control function would absorb all relevant firm heterogeneity. We then show that applying our estimator greatly reduces persistence in the residuals. Importantly to applied researchers, our estimator easy to implement, as described in the online Appendix S1. An approximation of the control function allows for an uncomplicated GMM procedure which can be implemented using the Stata ivreg2 command.

The advantages of CFE-FE notwithstanding, allowing for fixed effects can exacerbate the attenuation bias due to measurement error (Griliches and Hausman, 1986), which poses a potential tradeoff between the transmission bias in the conventional CFEs and the attenuation bias in CFE-FE. Addressing this tradeoff is left for further research. Currently, there is a case for caution in using our estimator when the persistent TFP component is weak and the extent of measurement error in the data is large. 


\section{References}

Ackerberg, D., Lanier Benkard, C., Berry, S. and Pakes, A. (2007). 'Econometric tools for analyzing market outcomes', in Heckman J. and Leamer E. (eds), Handbook of Econometrics, Vol. 6, chap. 63. North Holland: Elsevier.

Ackerberg, D., Caves, K. and Frazer, G. (2015). 'Structural identification of production functions', Econometrica, Vol. 83, pp. 2411-2451.

Ahn, S. C. and Schmidt, P. (1995). 'Efficient estimation of models for dynamic panel data', Journal of Econometrics, Vol. 68, pp. 5-28.

Arellano, M. and Bover, O. (1995). 'Another look at the instrumental variable estimation of error-components models', Journal of Econometrics, Vol. 68, pp. 29-51.

Aw, B.-Y. (2002). 'Productivity dynamics of small and medium enterprises in Taiwan', Small Business Economics, Vol. 18, pp. 69-84.

Bartelsman, E. and Doms, M. (2000). 'Understanding productivity: lessons from longitudinal microdata', Journal of Economic Literature, Vol. 38, pp. 569-594.

Blundell, R. and Bond, S. (1998). 'Initial conditions and moment restrictions in dynamic panel data models', Journal of Econometrics, Vol. 87, pp. 115-143.

Blundell, R. and Bond, S. (2000). 'GMM estimation with persistent panel data: an application to production functions', Econometric Reviews, Vol. 19, pp. 321-340.

De Loecker, J. D. and Warzynski, F. (2012). 'Markups and firm-level export status', American Economic Review, Vol. 102, pp. 2437-71.

Eberhardt, M. and Helmers, C. (2010). "Untested Assumptions and Data Slicing: A Critical Review of FirmLevel Production Function Estimators", Economics Series Working Papers 513, University of Oxford, Department of Economics.

Gandhi, A., Navarro, S. and Rivers, D. (2011). "On the Identification of Production Functions: How Heterogeneous is Productivity?” Discussion Paper 20119, University of Western Ontario, CIBC Centre for Human Capital and Productivity.

Griliches, Z. and Hausman, J. (1986). 'Errors in variables in panel data', Journal of Econometrics, Vol. 31, pp. 93-118.

Griliches, Z. and Mairesse, J. (1998). 'Production functions: the search for identification', in Strøm S. (ed.), Econometrics and Economic Theory in the Twentieth Century: The Ragnar Frisch Centennial Symposium, New York: Cambridge University Press, pp. 169-203.

Huang, G. and Hu, Y. (2011). "Estimating Production Functions with Robustness Against Errors in the Proxy Variables", CeMMAP Working Papers CWP35/11.

Kasahara, H. and Rodrigue, J. (2008). 'Does the use of imported intermediates increase productivity? Plantlevel evidence', Journal of Development Economics, Vol. 87, pp. 106-118.

Lee, Y. (2014). 'Nonparametric estimation of dynamic panel models with fixed effects', Econometric Theory, Vol. 30, pp. 1315-1347.

Lentz, R. and Mortensen, D. T. (2008). 'An empirical model of growth through product innovation', Econometrica, Vol. 76, pp. 1317-1373.

Levinsohn, J. and Petrin, A. (2003). 'Estimating production functions using inputs to control for unobservables', Review of Economic Studies, Vol. 70, pp. 317-341.

Munch, J. R. and Skaksen, J. R. (2008). 'Human capital and wages in exporting firms', Journal of International Economics, Vol. 75, pp. 363-372.

Olley, G. S. and Pakes, A. (1996). 'The dynamics of productivity in the telecom- munications equipment industry', Econometrica, Vol. 64, pp. 1263-97.

Pavcnik, N. (2002). 'Trade liberalization, exit, and productivity improvements: evidence from chilean plants', Review of Economic Studies, Vol. 69, pp. 245-276.

Petrin, A. and Levinsohn, J. (2013). 'Measuring aggregate productivity growth using plant-level data', RAND Journal of Economics, Vol. 43, pp. 705-725. 
Stoyanov, A. and Zubanov, N. (2012). 'Productivity spillovers across firms through worker mobility', American Economic Journal: Applied Economics, Vol. 4, pp. 168-98.

Stoyanov, A. and Zubanov, N. (2014). 'The distribution of the gains from spillovers through worker mobility between workers and firms', European Economic Review, Vol. 70, pp. 17-35.

Syverson, C. (2011). 'What determines productivity?', Journal of Economic Literature, Vol. 49, pp. 326-365.

Wooldridge, J. M. (2009). 'On estimating firm-level production functions using proxy variables to control for unobservables', Economics Letters, Vol. 104, pp. 112-114. 